\title{
LA CUESTIÓN DOBLE DEL FUNDAMENTO Y EL PRINCIPIO DE IDENTIDAD EN LAS LECCIONES DE ERLANGEN DE F. W. J. SCHELLING ${ }^{1}$
}

\author{
MIGUEL ÁNGEL RAMÍREZ CORDÓN \\ Universidad Complutense de Madrid
}

\begin{abstract}
RESUMEN: Sobre la base de las Lecciones de Erlangen, se trata de analizar cuál es el procedimiento por el que se construye en la filosofía de Schelling el concepto de libertad. Libertad que, según el Freiheitsschrift, es la capacidad de elegir entre el bien y el mal, no es en el fondo más que el procedimiento por el que el fundamento de la ciencia y el principio de identidad quedan divididos. Esta división no es en cambio una fisura que marca la independencia entre ambos términos, sino que, al contrario, fundamento e identidad guardan una relación de antecedente y de consecuente respectivamente, ocupan dos tareas, dos competencias distintas, y cuyo trabajo conjunto y final es precisamente fruto de la libertad.
\end{abstract}

PALABRAS CLAVE: fundamento; identidad; magia; éxtasis; libertad.

\section{The double question of the foundation and the principle of identity in F. W. J. Schelling's Erlangen Lectures}

ABSTRACT: Based on the Lessons of Erlangen, it is going to be analyzed what is the procedure by which is built on Schelling's philosophy the concept of freedom. Freedom which, according to the Freiheitsschrift, is the capacity to choose between good and evil, it is not in deed, but the process by which the foundation of science and the principle of identity are divided. The division is not however a rift that marks the independence between the two terms but, on the contrary, foundation and identity have a relationship of antecedent and consequent respectively, they occupy two tasks, two different competences, and whose whole job is only the final fruit of freedom.

KEY WORDS: fundament; identity; magic; extasis; freedom.

\section{INTRODUCCIÓN}

Andrew Bowie recuerda convenientemente que el título con que rotuló el alumno que asistió al curso de 1820/1821 impartido por Schelling en Erlangen es Initia Philosophiae Universae ${ }^{2}$. Este manuscrito sería llevado a imprenta por el hijo de Schelling, y el título que este escogería para presentar el texto de su padre, y que todavía hoy podemos leer en muchas ediciones, es De la naturaleza

1 El presente trabajo es resultado de una estancia de estudios doctorales cursada en el Institut Supérieur de Philosophie de la Universidad Católica de Lovaina, cursada bajo la tutela del profesor Marc Maesschalck de septiembre de 2015 a enero de 2016.

BowIE, A.; Schelling and Modern European Philosophy, Routledge, London, 1993, p. 130. 
de la filosofía en tanto que ciencia. La misma paradoja que albergan estos dos títulos tan diversos, es asimismo la que contienen las distintas lecturas que de las Lecciones de Erlangen podrían darse. En ese sentido cabe preguntar si el inicio mismo de la filosofía es análogo a la filosofía constituida ya como ciencia, o si por el contrario se trata de dos estadios distintos y distantes de la misma filosofía, y en modo alguno conmensurables entre sí. A este tenor estas Lecciones han sido vistas por varios especialistas como los prolegómenos de la filosofía positiva de Schelling. Hay que analizar con cuidado si este paso a un proceder distinto del método filosófico implica o no el olvido del cometido de la producción inicial del filósofo de Leonberg ${ }^{3}$, momento en el que es preponderante su preocupación por el fundamento o por la pregunta, en definitiva, de cómo y por dónde ha de comenzar la filosofía. La propuesta de este artículo es demostrar que, en Schelling, el fundamento es inseparable del curso de la ciencia, y que no puede haber ninguna ciencia que no tenga como cimiento un fundamento perenne.

\section{ORIGEN Y DESTINO: SOBRE LA DisPaRIDAD DEL FUNDAMENTO Y LA IDENTIDAD}

En la primera línea de las Lecciones asistimos a la aseveración de que el anhelo de encontrar el edificio entero del saber humano obliga a concluir que dicho sistema no está dado. Sólo existe de momento y al menos la pregunta por su posibilidad, pero la forma de la pregunta rehúye el saber, por más que el saber mismo pueda estar apuntado en la formulación de la pregunta. El sonido ascendente de la pregunta hace evacuar cualquier contenido firme, espanta a todo aquello que pudiera guarecerse en la afirmación. Pero en cambio preguntar busca más bien la seguridad del hogar, la firmeza de los cimientos. Por tanto, nada hay aún excepto el ansia de poder afirmar, nada excepto la duda que alberga la pregunta. El sistema

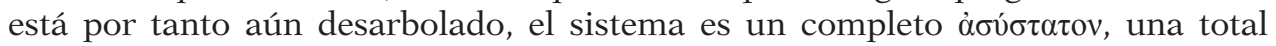
indeterminación, no se sabe aún qué forma puede llegar a adoptar el edificio. Pero sí ha sido plantado su germen: el preguntar constante, incansable, endémico.

Cualquier sistema por tanto que vaya apareciendo en la investigación será sencillamente un mero ensayo, deberán ser realizadas diversas pruebas hasta llegar al Sistema completo, acabado, y cada tentativa deberá ser necesariamente anterior al Sistema final. Con ello está supuesto que pueden llegar a coexistir varios sistemas a la vez, así como el empirismo se opone al idealismo o el criticismo viene a hacerlo frente al dogmatismo. Esta oposición no es gratuita, sino que se funda en razones

\footnotetext{
3 Cercanos a esta postura parecen ser PAREYSON en Ontologia della libertà. Il male e la sofferanza, Einaudi, Torino, 1995, 408, pero fundamentalmente SNow, D. E.; Schelling and the End of Idealism, SUNY, New York, 1996, pp. 168-169, pero en general en toda la obra, donde se incide en la idea de que Schelling liquida el concepto de fundamento, lo cual lo coloca ya en una postura anti idealista. La razón parece ser que la naturaleza es vista por Schelling como lo que no admite fundamento, y que (o porque) éste no puede ser accesible a la inteligencia (pp. 139-140). Como mostraremos más adelante, la naturaleza es libre respecto del fundamento, pero sin dejar por ello de depender de él. Para un platónico como Schelling, del hecho de que no pueda verse el fundamento de algo, como cualquier idea concreta, no puede deducirse que éste no exista.
} 
objetivas, así como el empirismo no puede dar un paso sin previamente haber coleccionado uno tras otro todos los acontecimientos dados, y el idealismo supone que esos datos deben ser coordinados por un sujeto transcendental, y ello supone ya problemas que no son exclusivamente teóricos, sino que están directamente enclavados en el centro mismo de la realidad, donde los objetos de conocimiento brindan más bien la oportunidad de sentar ciertas posiciones ontológicas, lo cual es imposible mientras los objetos no se han hecho presentes. La idea de Sistema por tanto supone la lucha encarnizada, la pugna a muerte entre distintos modos de arrostrar el mundo, donde el Sistema es la última parada, estando siquiera todavía más allá de cualquier estación, libre de todo sistema, pero que deviene posible sobre la base de la irrupción de la disputa.

Esta lucha entre sistemas encuentra su raíz en la contradicción que constituye el saber humano. Pero no hay escapatoria a este modo de conocer, es nuestra única herramienta. No sabemos verdaderamente nada definitivo, y en el fondo no sabemos más que preguntar sobre aquello que queremos saber. Preguntar pone de manifiesto precisamente nuestra menesterosidad, pero preguntar al mismo tiempo revela algo de aquello a lo que nos conducimos, de modo que seguir esta misma contradicción implícita en el preguntar y un responder que no termina de adecuarse a la pregunta debe ser el método más conveniente que pueda conducir «a la idea de este Todo superior» ${ }^{4}$.

Esta contradicción impulsa a dirigirse hacia el Sistema. La contradicción misma es por tanto movimiento o implica movimiento, como ya habían sentado Las edades del mundo ${ }^{5}$. Ahora bien, el movimiento, la naturaleza progresiva de los sistemas particulares, constituye una presuposición, la primera de las que van a ser planteadas en estas lecciones. En cambio, el movimiento no es algo con lo que debamos contar, sino que nos encontramos ya con él; es decir, actúa como un efecto, como un resultado de la contradicción del saber humano. Podría por tanto sostenerse que es la existencia de la contradicción la primera de las presuposiciones. Pero, en cambio, es al contrario, la contradicción se coloca ya como Faktum, como un hecho incontestable. Ocurre que las determinaciones a que dan lugar los diversos sistemas finitos deben ser puestos en suspenso, debe aplicárseles una cuarentena hasta llegar a saber si sus afirmaciones se concilian o no con la verdad, o hasta saber al menos cuál es el lugar específico que ocupan en el conjunto del Sistema, del saber Total. Pero como se está queriendo connotar, este Sistema viene al final. Es por

4 Schelling, F. W. J.; Schellings Werke, (Schröter, M., Hg.), C. H. Beck/ R. Oldenburg, 1966, München, V, p. 8. Se abreviará a continuación como $S$. W. A la hora de trabajar el texto de las Lecciones de Erlangen se ha cotejado la traducción de S. Jankélévitch para ScheluING, F. W. J.; «De la nature de la philosophie en tant que science», en Essais de Schelling, Aubier, Montaigne, 1946, p. 528.

5 S. W., Nachlaß Band, pp. 39-40; trad. Schelling, F. W. J., Las Edades del Mundo, en Schelling, Gredos, Madrid, 2012, p. 339. No citamos Las Edades del Mundo por una mera sofistificación erudita, sino porque la noción de contradicción de este texto es la base sobre la que se construye la argumentación del Sujeto absoluto de las Lecciones de Erlangen como lo indefinible por antonomasia al encontrarse precisamente no en el ámbito de ninguna definición dogmática, sino en el movimiento mismo que transita entre la afirmación y la negación, situándose así como punto de arranque de la libertad misma que constituye la unidad de las determinaciones. A este respecto puede consultarse LoER, B.; Das Absolute und die Wirklichkeit in Schellings Philosophie, Walter de Gruyter, Berlin, 1974, p. 235 y ss. 
ello por lo que debe suponerse que cada una de las figuras preliminares del saber conducen a algún lugar, conducen, o deben al menos guiar, hacia el saber absoluto. Mientras tanto las afirmaciones de los sistemas particulares están desintonizadas entre sí, son por tanto contradictorias entre sí. No hay por tanto contradicción sin movimiento previo. De este modo, el sistema gravitacional expuesto por Copérnico supone una auténtica revolución en el modo de comprender los fenómenos relacionados con el movimiento heliocéntrico, y el nacimiento propiamente dicho de la astronomía moderna, y sus tesis permanecerán prácticamente incontestadas hasta la acomodación sistemática de El sistema del mundo de Newton, cuyos trabajos quedarán igualmente en entredicho ante la fulminante aparición de la teoría de la relatividad especial de Albert Einstein. En suma, cada uno de estos sistemas son verdaderos hasta cierto momento, de un modo preliminar tan sólo, a partir de cuando son sustituidos por teorías más verosímiles. Posiblemente Schelling se esté refiriendo a esto cuando afirma que una proposición dada puede ser verdadera en un momento determinado, y no serlo por más tiempo en otro momento diferente ${ }^{6}$.

Es pertinente en este punto sacar a la palestra, y poner en relación con la primera, la segunda presuposición que plantea Schelling en este curso, y que sigue a la primera; es decir, que el sistema comporta varias partes, pero un único sujeto ${ }^{7}$. Si esto es así, una posible opción es que el sujeto deje inmediatamente de ser igual a sí mismo, para pasar a ser distinto en cada momento de la producción del saber. En efecto, el sistema es fruto del sujeto, el saber coordinado, el saber que es capaz de localizar aquello que hay de común en ciertas leyes de la física, de la química, así como en ciertas teorías historiográficas, literarias, antropológicas, políticas, etc.; es decir, dicho con el lenguaje de la época, el saber absoluto, es enunciado en todo momento por el mismo y único sujeto; esto es, el fundamento de la ciencia permanece inalterado, pero en cambio la estructura de la ciencia no es inmediata sino procesual, temporal, y el sujeto acompaña a cada una de la etapas de este saber inicialmente particular, limitado, de modo que el sujeto es tanto $\mathrm{A}=\mathrm{B}$, como $\mathrm{A}=\mathrm{B}^{1}, \mathrm{~B}^{2}$, $\mathrm{B}^{3}$, como $\mathrm{A}=\mathrm{C}, \mathrm{A}=\mathrm{D}$, y así sucesivamente. De manera que, si este sujeto se mueve con la misma celeridad que la ciencia, no parece que pueda detenerse un momento para poder analizar sus características y enunciar sus notas fundamentales. Este sujeto, dice Schelling, es indefinible, dado que "tampoco es nada, porque él es todo» ${ }^{8}$. Pero ni es ninguna suerte de totalidad, como tampoco es una mera nada, sino más bien libertad para ser todo ello o no serlo. Ceñirse en definitiva a cada una de estas fórmulas, separadamente o al mismo tiempo, obligaría a dejar fuera algo a lo que el Yo tiene la particularidad de poder penetrar por dentro y atravesar definitivamente,

\footnotetext{
${ }^{6} \quad$ S. W., V, p. 9; trad. Schelling, F. W. J.; «De la nature de la philosophie en tant que science», en Essais de Schelling, Aubier, Montaigne, 1946, trad. S. Jankélévitch, p. 529.

7 Schulz, W.; Die Vollendung des deutschen Idealismus in der Spätphilosophie Schellings, W. Kohlhammer Verlag, 1955, Stuttgart, pp. 100-101 ya expuso la contradicción en la que incurrían estas dos presuposiciones de las Lecciones de Erlangen, y el fruto de la «eterna libertad» que cabía esperar de la imposibilidad de conciliar estas dos proposiciones. Schulz más bien cita a Schelling y deja sin explicar hasta el fondo lo que nosotros nos proponemos aquí, que es dar en la cuenta de cómo pueda entenderse el concepto de libertad a resultas de aquella contradicción.

8 S. W., V, p. 11; trad. Schelling, F. W. J.; «De la nature de la philosophie en tant que science», en Essais de Schelling, Aubier, Montaigne, 1946, trad. S. Jankélévitch, p. 531.
} 
mientras lo que ocurre es que el sujeto es la posibilidad, dicho con una excelente fórmula de Claude Bruaire, de permanecer absoluta libertad ${ }^{9}$, donde se conserva al mismo tiempo la acepción de un puro reposo como de un puro movimiento.

Lo contrario sería poder llegar a aislar una naturaleza que es intrínsecamente inquieta, poder inmovilizarla, paralizarla y comenzar a extraer las primeras condiciones de su naturaleza. Ya no sería entonces un sujeto vivo, activo, sino una figura taxidermizada, una pieza de coleccionista, un concepto negativo, en suma, que puede llegar a ayudarnos a comprender en alguna medida cuáles son las características generales del sujeto y cuáles sus límites, pero que se ha de quedar siempre a medio camino en la tarea de alcanzar a comprender aquella naturaleza tan escurridiza. Sería como las criaturas de un museo paleontológico, cuya fisionomía podemos inspeccionar, pero con cuya mirada no podemos cruzarnos ya nunca más. Por el contrario, si quisiéramos más bien atribuirle una noción positiva, estaríamos entonces en la vía adecuada para llegar a comprender a este Yo absoluto, a este fundamento sin el cual ni siquiera podemos comprender aquello que conocemos ya indubitablemente. Schelling no puede rendirse, no puede conformarse con que este sujeto absoluto hacia el cual parecen conducir todos los intentos de definición quede simplemente como una suerte de ideal irrealizable, que sea radicalmente imposible comprender, que no pueda de ningún modo llegar a aprehenderse esta naturaleza, así como al mismo tiempo conservar la virginidad de algo tan frágil después incluso de haber rasgado su velo.

El fundamento (el sujeto absoluto en tanto que fundamento) es inaprehensible en la medida en que realmente no existe, así como existe este vaso o este libro, no tiene un lugar determinado como el cadáver recién enterrado o la hoja que arrastrada acompaña al curso del río. Pero indudablemente hay algo que es fundamento pues afloran incansablemente de su seno sus producciones. El fundamento es lo Unvordenkliche, lo «impreprensable», de donde en cambio salen juicios impulsados a cada instante, preguntas. Como explica Courtine ${ }^{10}$, este fundamento que crea, que hace posible la realidad, permanece propiamente, como su fuente, indeterminado, no se trata de lo tematizable, es sencillamente un lugar lógico a partir de donde cobran consistencia el resto de objetos. Pero al mismo tiempo este fundamento es lo viviente, pues debe compartir algo con aquello que va a producir para que sea conmensurable, para que sea posible la relación entre los objetos que discurren en el tiempo. Pero como, en cambio, se mantiene como trascendencia con respecto a aquello que va a crear, puede decirse también que es el ser originario, el Unwessen, lo que no es ser propiamente, pero sí el conducto mismo del ser. Schelling explica en la Panorama general de la literatura filosófica más reciente cómo funciona este fundamento, o este presupuesto, pues es algo más bien con lo que debemos contar de antemano ya que no es algo claramente perceptible o inteligible a priori. El ejemplo más próximo, ya que no se puede hablar de él más que con símiles o metáforas, es el del uso por Euclides de los axiomas o postulados ${ }^{11}$, los cuales son indemostrables, no se pueden más que dar por supuestos, confiar ciegamente en su promesa: de aquellos cinco sencillos

9 Bruaire, C.; Schelling ou la quête du secret de l'être, Éditions Seghers, Paris, 1970, p. 11.

10 Courtine, J.-F.; Extase de la raison. Essais sur Schelling, Galilée, Paris, 1990, pp. 243-244.

11 S. W., I, p. 368; trad. Schelling, F. W. J.; Panorama general de la literatura filosófica más reciente, Abada, Madrid, 2006, p. 161. 
principios afloran proposiciones geométricas infinita, incansablemente, una detrás de otra, siguiéndose claramente la siguiente de la anterior.

Markus Gabriel entiende este fundamento, de un modo muy parecido a Courtine, como espacio lógico, como lugar donde se producen las relaciones entre los ámbitos de todos los objetos de conocimiento, sin llegar él mismo a ser un ámbito como lo pueda ser el ámbito de los objetos de la física, de la biología, etc., sino que es tan solo, y nada menos, el espacio donde cabe producir, examinar y coordinar entre sí el conjunto entero de los objetos. El fundamento es, pues, el centro desde el que cabe elaborar la totalidad de las proposiciones sobre los distintos ámbitos del mundo sin que quepa atribuir al fundamento propiedad alguna, tal como si se tratara de un ente entre otros. El fundamento simplemente debe ser entendido como el sujeto que contiene de modo implícito o como antecedens el conjunto de estructuras lógicas que permite formular las leyes de los objetos que obtienen entonces la posición de contenido explícito o consequens ${ }^{12}$. No cabe más que calificar a este ámbito, distinto del resto entero de los ámbitos, pero más allá de cualquiera de ellos, como «hueco ontológico, el vacío por antonomasia» ${ }^{13}$, una nada sin la cual, sin embargo, no es posible decir nada, llegar a ningún sitio desde lo que es en el fondo ningún lugar. El fundamento, o según esta nueva acepción de espacio lógico, es la condición imprescindible del conocimiento, de poder escrutar y entender el ámbito de lo existente, mientras el fundamento permanece inescrutable, sin por ello dejar en todo momento de alumbrar. Este fundamento, este sujeto absoluto es la eterna libertad, es un sujeto infinito que se haya enclavado él mismo frente a lo Infinito. Es una libertad que, en cambio, no puede no estar en el ámbito del ser, y cuya libertad precisamente estriba en estar en el lado del ser, en regirlo más bien, dominarlo, administrarlo. Se trata pues de un sujeto ambivalente, donde se encuentra la duplicidad de ser y de noser al mismo tiempo, de no ser nada, y gestionar al mismo tiempo el itinerario del ser, y siendo precisamente en la medida en la que ordena los distintos ámbitos del ser, mientras él mismo no es nada como lo son el cántaro y el cartapacio ${ }^{14}$. El fundamento es así una natura anceps, la ambigüedad en que consiste la libertad pura ${ }^{15}$.

Cabe preguntar ahora qué relación guardan aquellos sistemas particulares de la primera presuposición en relación con el Sistema final al cual nos orienta la libertad absoluta, o por decirlo de otro modo, qué relación guardan con el principio de identidad, el momento en que todas las esferas de conocimiento están reunidas bajo una sola causa. Algo que es en sí mismo diferente a cada paso, que avanza

12 Carrasco Conde, A.; «Panteísmo y panenteísmo: Schelling, Schlegel y la polémica en torno al panteísmo», en Daímon. Revista Internacional de Filosofía 54, 2011, p. 108.

13 Gabriel, M.; «¿Contingencia o necesidad? Schelling y Hegel acerca del estatus modal del espacio lógico», en Ideas y valores, Vol. 59, nº 142, Bogotá, 2010, p. 8.

${ }_{14}$ HüHN, L.; «Ekstasis. Überlegungen zu Schellings Spekulationen über die Grenze menschliche Wissens», en Philosophie der Subjektivität? Zur Bestimmung des neuzeitlichen Philosophierens, Akten des 1. Kongresses der Internationalen Schelling-Gesellschaft, 2, BAUMGARTNER, H. M. y JAcoBs W. G. (Hrsg.), Frommann-holzboog, 1993, Stuttgart-Bad Cannstatt, p. 447, donde se constata en efecto la dificultad expuesta por Schelling en estas lecciones de poder definir a este sujeto absoluto, pero cuyas notas sí pueden extraerse de modo negativo, como el «pensamiento conceptual-discursivo» que pone en pie la realidad efectiva o positiva de un mundo.

15 S. W. , V, p. 14; trad. Schelling, F. W. J.; «De la nature de la philosophie en tant que science», en Essais de Schelling, Aubier, Montaigne, 1946, trad. S. Jankélévitch, p. 534. 
justo para adoptar determinaciones distintas para ganar una nueva configuración, debe ser justo lo opuesto al principio que reza $\mathrm{A}=\mathrm{A}$. En el fondo la estrategia emprendida aquí por Schelling, que no es distinta a la ya abierta en el Escrito de la libertad, es precisamente liberarse de la acusación de panteísta, acusación en todo caso injustificada a tenor de lo que va a ser expuesto aquí.

Afirma Schelling en el Freiheitsschrift a este tenor que el único panteísmo que ha podido coronar algún sistema de filosofía es el que, a fuerza de armar razonamientos geométricos, impecablemente lógicos, ha dejado fuera la libertad. Todo razonamiento que parte de un principio dado y despliega a partir de éste un conjunto de afirmaciones que sustentan aquel principio pero que, al mismo tiempo, encuentran en él su apoyo, en el fondo saturan el mundo mismo de una uniformidad sistémica que no se concilia realmente de un modo definitivo con ese mundo. Si fuera así, la cosmovisión de Ptolomeo, o el modelo atómico de Bohr podría en su día haber colmatado la explicación de ciertos problemas, pero la cuestión es que a Bohr le sigue Heisenberg y a Heisenberg le sigue Higgs, precisamente porque el mundo ofrece constante e indefinidamente un material que poder volver a ser examinado una y otra vez. Esta es una de las facetas en las que estriba la libertad desoída por aquellos sistemas calcificados que consideran el mundo como producto de la inteligencia sin que el mundo tenga una creatividad propia que poder ofrecer al observador que trata de escrutarlo ${ }^{16}$. Schelling trata de demostrar en las páginas del Freiheitsschrift que los fenómenos de la naturaleza se manifiestan con plena libertad ante nuestros ojos, y que con la misma libertad observamos el mundo para darle diversas explicaciones que pueden ir resolviendo poco a poco la multitud de cuestiones abiertas, pero que, al mismo tiempo, estos fenómenos no despiertan aleatoriamente y se entrecruzan a voluntad y con desconcierto, sino que todos tienen un mismo origen, todos dependen a fin de cuentas de un único y mismo fundamento, lo cual, lejos de anular la libertad del mundo, la alimenta:

Dicho principio no expresa una unidad que girando en el círculo de la igualdad no sería progresiva y por ello sí insensible y sin vida. La unidad de este principio es inmediatamente creadora. Ya en la relación de sujeto a predicado, hemos mostrado aquella del fundamento con la consecuencia, y el principio del fundamento es por ello tan originario como el de la identidad. Por eso mismo lo eterno debe ser también inmediatamente, y tal como es en sí mismo, fundamento. Aquello de lo que él es fundamento por su esencia, es un ser dependiente en esa misma medida y también, conforme al punto de vista de la inmanencia, un ser comprendido en él; pero la dependencia no anula la subsistencia por sí, ni tampoco ni tan siquiera la libertad. Sin determinar su esencia, indica sólo que lo dependiente, sea lo que sea, sólo pude ser consecuencia de aquello de lo que es dependiente; no dice lo que es ni lo que no $\mathrm{es}^{17}$.

En este riquísimo fragmento, no obstante, no se habla tan sólo de la relación de lo creado con respecto a su fundamento, sino que, pese a determinar su naturaleza como originaria, se dice que el fundamento y la identidad son algo diverso. Este problema lo plantea Schelling al comienzo de las Investigaciones precisamente como un

16 S. W., IV, p. 237; trad. Schelling, F. W. J.; Investigaciones filosóficas sobre la esencia de la libertad humana y los objetos con ella relacionados, Anthropos, Barcelona, 1989, trad. Helena Cortés y Arturo Leyte, p. 133.

17 S. W., IV, pp. 237-238; trad. p. 134. 
problema lógico, acuciante en su época, afirma Schelling, según el cual el sujeto y el predicado de una proposición deben resultar idénticos por medio de la atribución de igualdad que establece la cópula. Mientras, Schelling prefiere contemplar esta relación conforme a la manera de los antiguos, donde sujeto y predicado son más bien el antecedente y el consecuente, donde éste último depende del anterior en función a la relación que mantienen, sin por ello aniquilar la autonomía de cada uno de los términos de la correspondencia ${ }^{18}$. Este modo de entender la relación que establece el principio de identidad permite, como entre otros ha notado Bernard Freydberg ${ }^{19}$, poder fundar auténticamente un concepto de libertad que está taponado y no puede aún desplegarse en los sistemas panteístas, según el cual aquél consecuente gana autonomía por primera vez al verse no ya como idéntico a su fundamento, sino distinguido del mismo, pero al cual, en cambio, le debe la razón de su despliegue.

El concepto de libertad es sin duda el que más llama siempre la atención a cualquier lector, el que más nos arroba y llena de turbación al mismo tiempo. En el caso específico de Schelling la libertad constituye, como particularmente en todo el idealismo, un problema de primer orden. Multitud de escritos se han publicado sobre la libertad en Schelling. En cambio, la libertad en Schelling es más bien una consecuencia natural de un hecho previo, un producto final y necesario con el que mentar todo un proceso de argumentación desarrollado a lo largo de años. Esta tarea no es otra que la separación del fundamento y el principio de identidad, esta y ninguna otra es la gran epopeya en la que se embarca Schelling ya desde el mismo Sistema del Idealismo Trascendental ${ }^{20}$, poder explicar un concepto como el de libertad y revelar qué mecanismos deben movilizarse y ponerse a trabajar en semejante empresa. Libertad entonces no es nada más que el concepto con el que se cifra esta separación. El deslindamiento del fundamento y la identidad es la gran revolución en la filosofía de este momento, la proeza sin medida, entender en definitiva el principio de la identidad no como la base de los juicios analíticos, como ocurre en Kant, por tanto como una mera tautología, sino como «la esencia en sí misma sintética de la identidad ${ }^{21}$, descubrimiento típicamente idealista, como bien hace notar Heidegger, donde $\mathrm{A}$ = A en el fondo no está hablando sino de la modalidad concreta del ser, el modo como se presenta el ser, siempre por medio de algo ente, y por medio de lo cual reclama su identidad. De este modo libertad es pues simplemente el nombre con el que designar esta escisión, y hablar de libertad es hablar en definitiva de esta separación. Pero es gracias a esta separación del fundamento y de aquello que puede ser sabido que el fundamento mismo, el Yo, establece una relación con algo que supone una barrera (un No-Yo), un obstáculo que permite al fundamento re-conocerse como tal, y reafirmarse como identidad, no ya con respecto a sí mismo, sino con respecto al vínculo con lo otro de sí22. En

18 S. W., IV, pp. 233-239; trad. pp. 123-138.

19 FreydBerg, B.; Schelling's Dialogical Freedom Essay, SUNY, New York, 2008, pp. 21-25.

20 Düsing, K.; «L'histoire idéaliste de la conscience de soi dans le Système de l'idéalisme transcendental», en Schelling et l'élan du Système de l'idéalisme trascendental, L'Harmattan, Paris, 2001, p. 37.

${ }_{21}$ HeIdegger, M.; Identidad y diferencia, Anthropos, Barcelona, 2008, p. 65.

22 Fischвасн, F.; Du commencement en philosophie. Étude sur Hegel et Schelling, Vrin, Paris, 1999, p. 36. 
el momento en que el Yo consagra cada determinación de las cosas que tiene frente a sí $(\mathrm{A}=\mathrm{B} ; \mathrm{A}=\mathrm{C} ; \mathrm{A}=\mathrm{D}$, etc.), en el fondo revela en cada decir algo de algo que el sujeto es distinto del objeto que se le opone pero, al mismo tiempo, este objeto se convierte en propiedad del sujeto que se ha atraído a sí el objeto por medio de su decir algo de aquello que se le opone, que se le hurta, y que deja de estar alejado en el momento en que pasa a ser sabido ${ }^{23}$. En ese momento ya fundamento de la existencia y existencia dejan de ser ajenos, sino que se hermanan. Hay en efecto una distancia entre el primer «A»y el «A» que queda del otro lado de la cópula, es preciso ocupar más espacio de papel para designar su lugar a uno y otro término. Esta identidad que en el Sistema del Idealismo Trascendental recibe el nombre de autoconsciencia, en Erlangen es el acto de decisión del sujeto por medio del cual afirma su libertad, y en el procedimiento de negar cada cosa por medio de cada determinación, construye la secuencia de la historia de la ciencia que supone el curso por el que la conciencia, el fundamento que no daba lugar a ninguna determinación distinta de sí, se pone ahora como libre ${ }^{24}$.

¿En qué sentido entonces son ambos conceptos, el de fundamento y el de identidad, lo primigenio, mientras al mismo tiempo son lo que difieren entre sí? Sin duda se están tratando aquí dos sentidos diferentes de lo primero, así como el sol es origen de la luz, pero ésta inunda la tierra aún antes y todavía después de que el sol sea visible sobre el horizonte o se haya ocultado ya. Ciertamente, el fundamento es el principio originante en este sentido, la base de toda posterior fundación, la tierra horadada misma sobre la que se levantará algún día el edificio, y que en modo alguno es diferente de la zapata misma sobre la que reposa la estructura misma de la cimentación. El principio de identidad, en cambio, es algo también primero, pero en este caso sobre la base de una noción distinta, epistemológica en este caso. Fundamento e identidad son en efecto ambos principio de algo, pero no como es primero lo inmediato y lo absoluto bajo acepciones o puntos de vista distintos, tal como ya afirmaba Aristóteles ${ }^{25}$, y como hará Schelling desde Filosofía y religión ${ }^{26}$ como la base fundamental de lo que será la filosofía positiva. Por tanto, aquello que es primero porque se trate de lo incipiente para la intuición, es precisamente lo que aún no es claro, por más que pudiera ser distinto a los sentidos. Aquello que es recibido por los sentidos por tanto debe aún ser sometido al análisis riguroso del entendimiento, determinar verdaderamente qué tiene de semejante con respecto a otras cosas, y qué de desemejante, y a partir de ahí establecer cuáles son las notas dominantes de aquello que, al formularlas, permita mostrar en la investigación esa cosa y no otra. Esta última etapa es ya propiamente la de un tipo de identidad, y se trata necesariamente de una fase final del entendimiento. Pero esta identidad de que aquí se trata no es propiamente $\mathrm{A}=\mathrm{A}$, sino $\mathrm{A}=\mathrm{B}$. Es decir, A no es más que

23 S. W., II, p. 362; trad. Schelling, F. W. J., Sistema del Idealismo trascendental, en Schelling, Gredos, Madrid, 2012, p. 28: «En la proposición A = A no hay tal coincidir. Todo saber originariamente sobrepasa la identidad del pensar y el principio $\mathrm{A}=\mathrm{A}$ tiene que presuponer tal saber».

24 FischBAch, F.; o. c., p. 315, n. 22.

25 Aristóteles; Física, I, 1; Metafísica, V; Ética a Nicómaco, 1095b.

26 S. W. IV, p. 9; trad. Schelling, F. W. J.; Filosofía y religión, en Antología, Península, Barcelona, 1987. 
un sujeto o un predicado, siendo elementos intercambiables sólo bajo condiciones precisas ${ }^{27}$, pero nada hay que pueda establecer su adecuación aparte del «=», del es, a parte de la cópula. No otra sino la cópula es la identidad verdadera ${ }^{28}$. Pero no son menos importantes los elementos en liza en el juego de la cópula. En efecto A es idéntico a A'; es decir, no ya a sí mismo, sino al ente u objeto determinado de conocimiento y que se distingue por tanto de él ${ }^{29}$, siempre y cuando la cópula exponga las condiciones de la validez de ese juicio, pero el problema aquí es otro, y es que mientras A no sea igual a toda la serie de predicados, no de un modo consecutivo, sino inmediato, verdaderamente no hay identidad posible, o para decirlo con el lenguaje de la época, no hay Absoluto. ¿Pero cómo es ello posible si para establecer esta identidad plena es preciso zambullirse en el tiempo, en cada una de las determinaciones particulares que puede construir o llegar a construir el entendimiento en algún momento? Se abre aquí ya otro problema de un calado distinto: la posibilidad de pensar la libertad en el corazón mismo de la diferencia ${ }^{30}$.

27 Nos estamos refiriendo aquí a la relación de conceptos superiores y conceptos inferiores, o a la relación recíproca de género y especie en el caso de la extensión de los conceptos, o a las reglas de conversión respecto a las inferencias del entendimiento. Entre otros lugares, puede verse KANT, I.; Lógica, Akal, Madrid, 2000, pp. 146-147 para el primer caso, e ibidem, pp. 161-162 para el segundo.

28 A este respecto es Schelling mismo quien incide en el Sistema del Idealismo Trascendental (S. W., II, pp. 365-373; trad. Schelling, F. W. J., Sistema del Idealismo trascendental, en Schelling, Gredos, Madrid, 2012, p. 30) sobre la importancia no tanto de los términos que se relacionan en la predicación, como la cópula misma de la predicación, el término medio que es el único que puede establecer el criterio de la igualdad de sujeto y predicado, y que recibe el nombre de sujeto, debiéndose entender no el sujeto particular que percibe la realidad, sino el sujeto absoluto que se coloca como centro que emite el juicio de la síntesis de los términos colocados a uno y otro lado de la cópula. Es también una de las diferencias en las que estriba la separación de la posición de Fichte y de Schelling con respecto al principio de Identidad, como bien ha visto Schlanger, J.; Schelling et la réalité finie. Essai sur la philosophie de la Nature et de l'Identité, P.U.F, Paris, 1966, pp. 115-116.

29 Hamilton Grant, I.; "Philosophy become genetic": The Physics of the World Soul», en The new Schelling, Norman, J. y Welchman, A. (eds.), Continuum, London, 2004, pp. 142-144, donde se explican dos posibles conceptos de identidad, uno dinámico, en el que está en juego el tipo de juicios que pueden establecerse en torno a entidades individuales, y otro trascendental que implica directamente al sujeto. El último es la «identidad misma», pero la identidad debe desfondarse, debe separarse del fundamento para poder reconocerse como identidad precisamente en el orden de los elementos individuales que son diferentes unos de otros. En esta misma línea va el libro ya clásico recién citado de ScHLANGER, J.; o. c., p. 29 y §, n. 28.

30 En este punto, y en lo sucesivo cuando sea pertinente, nos vamos a referir también a la Filosofía Racional Pura, curso que Schelling dará en Berlín el año siguiente a haber impartido estas Lecciones de Erlangen aquí comentadas, para rescatar contenidos que en Erlangen son apuntados y en Berlín ampliados para iluminar mejor ciertos problemas que siguen siendo los mismos de Erlangen a Berlín. Así por ejemplo el hecho de que el principio que permanece guarecido en el pensamiento puro no puede salirse de los quicios del ente supremo y por tanto precisa liberarse de éste mismo para ser para sí y alcanzar así a revelar todas las posibilidades ocultas en el puro ente. S. W., V, pp. 568-569; trad. Schelling, F. W. J.; «Filosofía racional pura», en Introduction à la philosophie de la Mythologie, trad. GDR Schellingiana, Gallimard, Paris, 1998, p. 362. 


\section{LA LIBERTAD COMO FRUTO DE LA SEPARACIÓN DE FUNDAMENTO E IDENTIDAD}

En la sección anterior se decía que la libertad eterna era natura anceps. Pero, ¿cómo la libertad puede llegar a ser lo ambiguo por antonomasia? No debe entenderse la libertad según esto como lo impreciso, como lo vacilante, lo irresoluto. No es la libertad para escoger este u otro camino que se me abre al frente, sino la libertad de poder definir(los) en general, la capacidad de hacerlo de hecho, el poder prescribir con toda amplitud aquello que se puede determinar en algún momento, el "poder para el poder», no el interés o el deseo de todo capricho que pueda ofrecerse a la voluntad, sino la "voluntad en sí», dice Schelling ${ }^{31}$, la voluntad pura. O para decirlo con una terminología diferente, aunque no diversa, es el «ser fundamental inicial»" ${ }^{32}$, o la "voluntad del fundamento» ${ }^{33}$, el fundamento en definitiva, la base imprescindible que sirve de sustento para la determinación, ahora sí, de la voluntad de algo, y cómo ésta puede llegar a conducirse, cómo, hundida en el ámbito óntico, puede regir adecuadamente las distintas relaciones que se dan entre las cosas, o más bien si este intento de ordenación es errado o, si siendo correcto, en cambio no se determina por el conocimiento mismo del objeto, sino que el conocimiento claro de dicho ámbito deja de ser fin en sí mismo para convertirse en medio para otra cosa, en cuyo caso esa voluntad sería ya una voluntad enferma ${ }^{34}$, y no una voluntad movida por el amor, según la acepción con que se designa en Las Edades del Mundo al deseo de poner en relación diversos ámbitos de objetos particulares en relación con la Idea o el fundamento que actúa como su sustrato ${ }^{35}$. No es finalmente sino el amor el único que puede llegar a fundar el reino de una posible identidad acabada. Amor por tanto es, también en Erlangen, identidad, identidad que no está dada de una vez en el sujeto, en el fundamento, sino que debe ir gestándose gracias a la pericia del sujeto ${ }^{36}$. Nada ha sido ganado aún, por tanto, todo está por hacerse. Tampoco el fundamento garantiza el éxito de la empresa, el fundamento es tan sólo aquello gracias a lo cual podemos levantar el edificio que sea, sin caer tampoco en el engaño: un mal cálculo puede hacer descalabrarse el proyecto, y el fundamento no deja por ello de ser el mismo, nada ha cambiado, a parte de la obra que ha empezado a erguirse. El bien o el mal así, el cálculo exacto o el desviado, no están determinados de antemano, nadie ni nada dirige desde ninguna altura, desde ninguna órbita del más allá cuál haya de ser el curso de la historia o de una ciencia determinada. El

31 S. W., V, p. 14; trad. Schelling, F. W. J.; «De la nature de la philosophie en tant que science», en Essais de Schelling, Aubier, Montaigne, 1946, trad. S. Jankélévitch, p. 534.

32 S. W., IV, p. 267; trad. Schelling, F. W. J.; Investigaciones filosóficas sobre la esencia de la libertad humana y los objetos con ella relacionados, Anthropos, Barcelona, 1989, trad. Helena Cortés y Arturo Leyte, p. 205.

33 Idem.

34 Carrasco Conde, A.; «Ens alienum. El mal desde la Naturphilosophie en F. W. J. Schelling», en El vuelo del búho: estudios sobre filosofía del Idealismo, Del Luján di Sanza, S. y López, D. M. (eds.), Prometeo, Buenos Aires, 2014, pp. 241-266.

35 S. W. IV, pp. 686-687; trad. Schelling, F. W. J., «Las Edades del Mundo», en Schelling, Gredos, Madrid, 2012, p. 566.

36 Vetö, M.; Le fondement selon Schelling, Beauchesne, Paris, 1977, pp. 511-514. 
hombre es dueño de sí mismo, he ahí su realidad traumática, que «el vínculo de los principios [del bien y del mal] no es en él necesario, sino libre ${ }^{37}$.

No existen dos fundamentos, o dos voluntades, una que se deje embelesar por la razón y sea buena, y otra que enloquezca ante los impulsos de las inclinaciones y sea mala. Hay tan sólo una voluntad que está ligada al sujeto finito, que es quien podrá embriagarse por el bien y conducirse hacia él, o hacerlo por el contrario por el mal y seguir sus dictados. Pero, una vez más, Schelling no quiere decir expresamente que la libertad sea aquella función con la cual nos podemos conducir al bien o al mal, o que sea directamente agarrar la antorcha de las buenas obras, o estar de hecho ya degustando los placeres del crimen y de la transgresión. Libertad en Schelling no es más que la separación del fundamento de la existencia y de lo existente, la distinción entre el fundamento de que algo sea, y aquello que tengo ya frente a $\mathrm{mí}^{38}$, la separación, en una palabra, entre fundamento e identidad.

En esta misma línea Schelling dice que esta separación no fija más que la posibilidad del virtual recubrimiento de la voluntad de sus atribuciones, pero es de momento una división meramente abstracta, lo cual no quiere decir que no tenga consecuencias, pero no es todavía el plano del análisis de la realidad efectiva, aunque sin duda esta división preliminar es la condición imprescindible para la existencia de algo efectivo ${ }^{39}$. En ese sentido cabe entender esta libertad como todavía mera posibilidad de algo positivo, de modo que Erlangen no puede ser pensado como el terreno puramente de la filosofía positiva en tanto que enclavado en el terreno de la existencia. Tampoco se trata de que se estén pergeñando todavía los planos para la elaboración más adelante de la filosofía positiva ${ }^{40}$, sino que el hecho de que, por más que lo existente dependa de su fundamento, conserve al mismo tiempo su autonomía para el despliegue, debe suponer ya con toda plenitud la filosofía positiva. Así, en modo alguno la filosofía positiva es el planteamiento de la filosofía sobre el quicio de los problemas que plantean la existencia dando de lado a su dependencia del fundamento del conocimiento ${ }^{41}$. Esta posibilidad no es algo sobre lo que podría o no pensarse las cosas, sino que es más bien la misma condición gracias y por medio de la cual no estamos ya meramente en un plano sólo abstracto de consideración. En esto estriba la definición positiva del sujeto

37 S. W., IV, p. 266; trad. Schelling, F. W. J.; Investigaciones filosóficas sobre la esencia de la libertad humana y los objetos con ella relacionados, Anthropos, Barcelona, 1989, trad. Helena Cortés y Arturo Leyte, p. 203.

38 S. W., IV, pp. 264-265; trad. pp. 199-201.

39 S. W., IV, pp. 265-266; trad. Schelling, F. W. J.; Investigaciones filosóficas sobre la esencia de la libertad humana y los objetos con ella relacionados, Anthropos, Barcelona, 1989, trad. Helena Cortés y Arturo Leyte, p. 201.

40 Tilliette, X.; L'Absolu et la philosophie. Essais sur Schelling, PUF, Paris, 1987, pp. 74-75.

${ }^{41}$ En este sentido se posiciona MARquet, J.-F. en Liberté et existence: Étude sur la formation de la philosophie de Schelling, Gallimard, Paris, 1973, pp. 513-516. La misma opinión refleja Fischbach, F.; o. c., pp. 311-324, n. 22, con la diferencia de que, frente a Marquet, no es meramente la posición de la voluntad pura en el terreno del saber, sino más bien el acto de la voluntad de lanzarse a la filosofía ante la revelación de que su conocimiento es meramente negativo; es decir, que aún no sabe nada, tratándose de un impulso que viene por el movimiento de la decisión. 
tras la cual dice Schelling marchar ${ }^{42}$, en que la libertad en que consiste el sujeto no sea una mera fórmula, sino una propiedad con la que crear un mundo desde el principio, desde «cero»; es decir, poder salir de la conciencia atónita y producir la identidad a fuerza de unificar precisamente todo lo exterior en una unidad omnicomprensiva, de manera que tendremos fundada una filosofía positiva sólo en el momento en que el contenido de la existencia pueda conciliarse con aquellos presupuestos de la conciencia originaria, en el momento en que el fundamento de la existencia y la existencia misma, siendo distintos, se adecúen en cambio entre sí, en el momento en que naturaleza y libertad, fundamento e identidad, queden acoplados manteniéndose ambos al mismo tiempo en parámetros distintos ${ }^{43}$.

Si esta libertad que es el fundamento es por tanto posibilidad, pero posibilidad, eso sí, para lo concreto, posibilidad para el ente, esta libertad es entonces mögen, eterno mögen; es decir, eterno querer y eterno poder, pues mögen tiene en alemán la doble acepción de querer y de poder algo. Pero, aunque esta libertad es la posibilidad para querer algo, no habla Schelling de un vermögen, como haga Fichte o el propio Schelling cuando deben referirse a un primer poder o a un llegar a poder, de un poder hacer algo en algún momento, sino de un mögen ya activo, de la base de algo con lo que se puede operar, con lo que estamos ya actuando, conociendo, construyendo. Pero el construir es más bien el fruto del fundamento que tiene a su alcance mecanismos con los que allegarse a la realidad. Los productos que dejamos en el mundo, que podemos conocer, o malinterpretar, consumir, etc., están canalizados por la libertad, pero no es la libertad la que lanzamos más allá del alcance de nuestras manos. Curiosamente Schelling encuentra una raíz etimológica de la palabra germana mögen con la latina magie. Como dice Tilliette en su monografía ya clásica sobre Schelling ${ }^{44}$, esta noción de «la Magie» permite hacerse buena idea del funcionamiento de este poder, pues magia es inicialmente aquello que es indiferente, al contrario de lo que ocurre con el mago, que debe mover las manos para hacer brotar la magia. La magia simplemente produce sus encantos como de la nada, pero en efecto, aquél que sabe de la potencia de su poder, y tiene al mismo tiempo un pie puesto en el mundo, debe empezar a agitar los brazos para extraer los prodigios de sus manos. Lo mismo ocurre con el saber en reposo, hasta el punto de que magia y saber en reposo es casi decir lo mismo. El saber en reposo, como la magia antes de producir sus espejismos, se pone en marcha hacia aquello que ha de saber. Pero cuando por fin toca aquello que quiere saber, deja inmediatamente de conocerlo, pues debe saltar hacia un saber allende este primer saber que le permita entender a éste primero, y así ad infinitum. Se trata en todo caso del movimiento necesario que engendra la ciencia. Pero hay que ser precavido a la hora de no confundir el primer saber que aún no lo es de nada, que es verdaderamente no-saber, con el saber objetivo ya del primer «esto» $(q u o d)$. En ese sentido todo aquello que dejamos tras de nosotros en el mundo deja

$42 \quad$ S. W., V, pp. 12-13; trad. Schelling, F. W. J.; «De la nature de la philosophie en tant que science», en Essais de Schelling, Aubier, Montaigne, 1946, trad. S. Jankélévitch, p. 532.

43 S. W. II, pp. 595-596; trad. Schelling, F. W. J., Sistema del Idealismo trascendental, en Schelling, Gredos, Madrid, 2012, pp. 112-114.

44 Tilliette, X.; Schelling. Une Philosophie en Devenir. La Derniere Philosophie 1821-1854, Vol. II, Vrin, Paris, 1970, p. 144. 
en ese mismo instante de ser libre, pues pasa a estar en relación con el resto de condiciones, y ello mismo limita aquello frente a lo que se posiciona ${ }^{45}$. El mundo, así, adopta una forma determinada sometido a la libertad sin ser ello mismo libre sino más bien lo subordinado.

Por eso otra forma alternativa de referirse a este mögen, a esta eterna libertad, es con la palabra Sabiduría, el saber activo que sabe ya en todo momento cómo debe estar frente al mundo, así como el comerciante no tiene que preguntar a nadie para saber que el precio que debe poner a sus productos es el estipulado, o que alguien no debe mentir simplemente porque va de suyo ${ }^{46}$. O también como ante una pregunta de Sócrates el esclavo de Menón sabe ya inmediatamente qué debe dibujar o a qué figuras geométricas se está refiriendo el sabio ateniense ${ }^{47}$. Según esto no parece que sea un saber que pueda decirse «eureka, lo he encontrado», pues verdaderamente no tendríamos esa certeza si Sócrates no le hubiera preguntado al esclavo, pero si el esclavo acierta las complicadas preguntas del filósofo, es sin duda porque el esclavo ya conoce de lo que le está hablando el docto desde el comienzo. Pero acaso incluso llegamos a saber que el esclavo no es estulto cuando al terminar de formular las cuestiones que tiene preparadas Sócrates, el esclavo acierta uno tras otro cada uno de los problemas. Esta sabiduría implícita del esclavo que no ha podido nunca leer o asistir a las lecciones de los profesores, se acerca en algún sentido a aquella Sabiduría del Antiguo Testamento de que habla Schelling que no se da al comienzo, en el medio o al final, sino que es precisamente el inicio, el medio y el fin, que no se encuentra en ningún momento determinado, sino con total indiferencia e invariabilidad en cada uno de ellos. Y de esta sabiduría que está conociendo inmediatamente el mundo a la par que transita por el mismo, se puede decir que está conociendo de un modo simultáneo y paralelo al crecimiento del mundo; es decir, con-ciencia. Conciencia pues que es una con el mundo y que se despliega desde y con la Creación ${ }^{48}$. O también, finalmente, otra manera de referirse a esta facultad es con el término razón, el elemento completamente impersonal pero que se da de un modo eterno en cada sujeto particular, y con el cual tenemos la capacidad de poder conocer el mundo ${ }^{49}$.

45 S. W., II, pp. 668-669; trad. Schelling, F. W. J.; Escritos sobre filosofía de la naturaleza, Alianza, Madrid, 1996, pp. 206-208.

46 KANT, I.; Fundamentación de la metafísica de las costumbres, RSEM, Madrid, 1992, trad. Manuel García Morente, pp. 78-79.

47 Platón, Menon, 82b5-82e7.

48 Dugue, F.; Historia de la Filosofía Moderna. La era de la crítica, Akal, Madrid, 1999, p. 924, de quien queremos resaltar la importancia, como la tiene para este artículo, de la necesidad de un mundo creado al cual está vinculado simultáneamente el proceso de conocer. Haciendo más hincapié en la naturaleza de la conciencia radicada en un mundo que debe ordenar y conocer, pero refiriéndose en el fondo a lo mismo, mucho antes Xavier Tilliette en $o$. c., p. 24, n. 40, y poco después Pareyson, L.; o. c., p. 392, n. 3, inciden en el concepto surgido en las Weltalter de Mitwissenschaft der Schöpfung («con-ciencia de la Creación») para expresar esta evolución del concepto de intuición intelectual en el que quiere remarcarse que no hay conciencia absoluta posible, ni por tanto libertad, sin el mundo.

${ }_{49}$ S. W., V, p. 661; trad. Schelling, F. W. J.; «Filosofía racional pura», en Introduction à la philosophie de la Mythologie, Trad. GDR Schellingiana, Gallimard, Paris, 1998, p. 445. 
Resulta entonces que el fundamento se nos ha mostrado como conciencia, como una conciencia radicada en nosotros ${ }^{50}$. Esta conciencia es este nuestro poder que puede llevarnos a la ciencia, al único saber auténtico y verdadero, pero es en ese caso un poder que posee el yo finito, el yo particular de cada individuo, el poder de cada sujeto radicado en el mundo mismo donde sólo pueden conocerse cosas particulares. Pero este no es ni era el objeto de este curso, ni es lo que ansía la filosofía, sino que la filosofía busca sólo lo Absoluto ${ }^{51}$. Asimismo, ¿el ataque más furibundo de Schelling hacia Fichte no estribaba en que el Yo de éste último era finito porque el Yo al ponerse se conocía a sí mismo, y en ese mismo instante se ponía también como objeto ${ }^{52}$ No es, por otra parte, que Schelling, como afirma Marc Richir ${ }^{53}$, no se haya dado cuenta de que para Fichte este Yo también sea absoluto, como afirma en efecto decididamente en la Primera Introducción a la teoría de la ciencia ${ }^{54}$, sino que precisamente, por haber entendido hasta el fondo cómo funciona este Yo en Fichte, no le queda más que concluir que su Yo no era absoluto como pretendía Fichte, pues este Yo se tiene a sí mismo como primer conocimiento firme, y por tanto este Yo se transforma en ese mismo instante en su misma materia de conocimiento, por tanto en una figura de la finitud. Pero, ¿y en el caso de Schelling? ¿No dice él mismo que B, la conciencia finita, es el fondo de A, el fondo de la conciencia absoluta, de la libertad eterna, del puro mögen ${ }^{55}$ ¿Ha dejado ya de ser el fundamento lo primero para ser resultado? Sí y no. Por ello mismo el fundamento, esta libertad eterna, es lo ambiguo, no lo balbuciente, como hemos apuntado arriba, sino lo ambivalente, que no lo contradictorio, sino lo que puede estar siendo distintas cosas según el registro del discurso que estemos empleando.

Más bien hay que pensar esta conciencia finita no como lo primero o anterior con respecto a la conciencia absoluta, sino más bien como base, como soporte de la libertad. Es precisamente porque el sujeto absoluto tiene relaciones objetivas que puede llegar a conocerse, pues al contrario sería tener un absoluto que no se tendría más que a sí mismo, girando sobre sí mismo como gira el derviche hasta perderse completamente en sí mismo, perdiendo en definitiva la noción de ningún contacto de afuera, ni siquiera, en su estado de paroxismo, del suelo que le permite girar. Esta libertad absoluta debe afirmarse como sujeto, pero si no puede establecer una cópula más que consigo mismo, entonces ocurre que este sujeto está

50 S. W. V, p. 15; trad. Schelling, F. W. J.; «De la nature de la philosophie en tant que science», en Essais de Schelling, Aubier, Montaigne, 1946, trad. S. Jankélévitch, p. 535.

$51 \quad$ S. W., I, pp. 51-52; trad. Schelling, F. W. J.; Über die möglichkeit einer Form der Philosophie überhaupt, en Experiencia e historia: escritos de juventud, Tecnos, Madrid, 1990, pp. 38-39.

52 S. W., V, pp. 160-165; trad. Schelling, F. W. J.; Lecciones muniquesas para la historia de la filosofía moderna, Edinford, Málaga, 1993, pp. 187-191.

53 Richir, M.; "Inconscient, nature et mythologie chez Schelling», en Schelling et l'élan $d u$ Système de l'idéalisme trascendental, L'Harmattan, Paris, 2001, p. 181.

${ }_{54}$ Fichte, J. G.; Introducciones a la Doctrina de la ciencia, Tecnos, Madrid, 1997, p. 46 y ss.

55 S. W., V, p. 29; trad. Schelling, F. W. J.; «De la nature de la philosophie en tant que science», en Essais de Schelling, Aubier, Montaigne, 1946, trad. S. Jankélévitch, p. 548. 
paralizado por la misma imposibilidad de conocer nada que no sea a sí mismo ${ }^{56}$. Esta es la figura en la que Fichte se ve enrocado y de la que no puede terminar de salir hasta el final de sus días. No debe el Yo conocerse entonces tan sólo como sujeto, pues entonces no se está conociendo en el fondo más que como objeto, ese ha sido el gran descubrimiento del Vom Ich de Schelling. Este sujeto no puede pues vislumbrarse, una vez arrojado fuera, como un objeto entre otros. No se trata de un ámbito de objetos entre otros. En cambio, ha de ser precisamente la verdad de los objetos mismos, la posibilidad de estructurar la realidad de los objetos adecuadamente; esto es, con verdad, de modo que si todos los objetos vienen a responder con su verdadera esencia a quien se acerca a contemplarlos, el sujeto es entonces la verdad eterna. Este es el modo propicio de llegar a conocer al sujeto absoluto, precisamente mientras está reconstituido a partir del objeto en tanto que sujeto, donde no es tan sólo sujeto, sino sujeto en tanto que objeto, y objeto en tanto que sujeto sin estar por ello, dice Schelling, «desdoblado» ${ }^{57}$. Es decir, no deja el sujeto de ser absoluto cuando está conociendo objetos, sino que precisamente estos objetos pueden ser determinados porque están siendo reunidos por un poder absoluto, por la potencia absoluta, la libertad eterna de la conciencia, pero es a la vez mientras está conociendo, y no hasta entonces, que el sujeto reconoce su poder efectivo. Y por ello es por lo que el sujeto no se puede conocer, no en tanto que fundamento, sino en tanto que identidad completa, ni al comienzo (donde no es más que un saber puro, informe), ni durante el período de creación de la ciencia (pues todavía no se alberga con seguridad la envergadura de la misma), sino sólo al final. En este instante el sujeto finito no puede hacer otra cosa que reconocerse como tabla de trabajo en la que opera el Yo absoluto, donde el primero desaparece en detrimento del fundamento primero, sin que por otra parte el Yo absoluto pueda manifestar su poder sino por medio de su sustrato finito ${ }^{58}$.

Respecto a su naturaleza en tanto que fundamento, como hemos indicado arriba, no debe cursarse en la existencia para poder actuar, se pone en marcha justo porque no puede hacerlo de otra manera, porque se trata de un fundamento estante pero ansioso, pero al soltar el proceso de conocer el mundo se reconoce al final, conociendo el mundo, precisamente como Espíritu, como fundamento que no ha dejado de serlo, pero reconociendo por fin su obra maestra, reconociéndose como lo más preciado de la Creación entera ${ }^{59}$, no ya por tanto como mera potencia ocluida, como proyecto prístino en ciernes de derramarse en el mundo, sino ya como pura dynamis que contiene en sí la energeia con la que reconectar cada ámbito

56 Una exposición de esta crítica, según la cual el Yo fichteano aparece como principio absoluto al precio de estar separado de las cosas, puede localizarse en $S$. W., V, pp. 160168; trad. Schelling, F. W. J.; Lecciones muniquesas para la historia de la filosofía moderna, Edinford, Málaga, 1993, pp. 187-194. También en S. W., V, pp. 550-553; trad. Schelling, F. W. J.; «Filosofía racional pura», en Introduction à la philosophie de la Mythologie, trad. GDR Schellingiana, Gallimard, Paris, 1998, pp. 347-348.

57 S. W., V, p. 20; trad. Schelling, F. W. J.; «De la nature de la philosophie en tant que science», en Essais de Schelling, Aubier, Montaigne, 1946, trad. S. Jankélévitch, p. 539.

58 Kоколzка, V.; La médiation de l'expérience, Cerf, Paris, 2005, pp. 87-89.

59 BRIto, E.; La création selon Schelling, Leuven University Press, Louvain, 1987, pp. 409-410. 
de objetos del mundo ${ }^{60}$, y a su vez conectar unos y otros entre sí, liberando de esta manera el carácter de Dios mismo, desatando ahora su limpidez en una naturaleza de cuya mezcla surge la identidad verdadera de $\mathrm{A}=\mathrm{A}$, bajo cuya fórmula aparece como reconcentrada, o finalmente acallada su significación por esta unidad mucho mayor, el Yo $=\mathrm{Yo}^{61}$.

Schelling propone una nueva ecuación bajo la que entender los elementos en relación en este sujeto absoluto que logra serlo por fin gracias a haber realizado exitosamente la identidad en el mundo por medio de su poder, por medio de su fundamento que no es más que el motor constante que no quiere más que el mundo, pero, más aún, que no puede otra cosa más que quererlo, donde debe entenderse por ello comprenderlo, amarlo hasta entrelazarse con él hasta tal punto que en el abrazo resulten como uno solo ${ }^{62}$ :

B

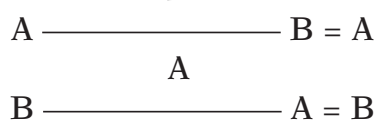

Son dos las líneas que traza Schelling pues, en efecto, acorde a la lectura que hemos realizado, y tal como reconoce Schelling más adelante, se ha efectuado una escisión entre el sujeto absoluto y el saber; es decir, la potencia que tiene el cometido de llegar a coronar la identidad absoluta en el curso de la existencia. Debemos así ver en la primera la línea sobre la que se construye el término del fundamento, y en la segunda la línea sobre la que se construye el principio de identidad, al tiempo que guardan entre sí una relación correlativa ${ }^{63}$. El sujeto absoluto así (A) debe ser visto como sujeto absoluto que, al ponerse en marcha a través de los instrumentos y facultades a su alcance, deviene objeto (B), pero siendo conocido, B, al mismo tiempo, deviene A; es decir, aquello que era simple materia informe resulta, al serle impuestas las categorías del sujeto, un objeto de conocimiento, deviene saber (A). Pero en un tercer momento A, que había devenido por un momento objeto, surgirá

${ }^{60}$ En la Filosofía racional pura se refiere específicamente a esta relación que mantiene la dynamis en tanto que fundamento o potencia, lo simple universal, que debe realizarse en la efectividad para poder dar un contenido a su pura forma, a partir de donde sería un alma completa y realizada, una energeia, $S$. W., V, pp. 473-474, pp. 560-561; trad. Schelling, F. W. J.; "Filosofía racional pura», en Introduction à la philosophie de la Mythologie, trad. GDR Schellingiana, Gallimard, Paris, 1998, p. 278, pp. 355-356.

${ }_{61}$ Roux, A.; "Puissance et malheur du Moi dans le "Système del'idéalisme trascendental”", en Schelling et l'élan du Système de l'idéalisme trascendental, L'Harmattan, Paris, 2001, p. 147.

${ }_{62}$ S. W., V, p. 27; trad. Schelling, F. W. J.; «De la nature de la philosophie en tant que science», en Essais de Schelling, Aubier, Montaigne, 1946, trad. S. Jankélévitch, p. 546.

${ }_{63}$ La apuesta de un concepto de identidad como principio de duplicidad donde el Absoluto se juega en ser de un modo indiferenciado Sujeto de la predicación, y al mismo tiempo, el objeto designado por el juicio está presente en la Forschug de un modo temprano en los estudios tempranos de Paul Tillich sobre la filosofía de Schelling. En Tillich, P.; Mystik und Schuldbewußtsein in Schellings philosophischer Entwicklung, en Frühe Hauptwerke. Gesammelte Werke, Band I, Evangelisches Verlagswerk, 1959, Stuttgart, p. 59 y ss. 
nuevamente incorporado como sujeto cuando reconoce que es él quien impone al objeto sus condiciones. Por ello B se convierte en A, y A lo hace en B. Aquella unidad por tanto a la que nos referimos al hablar arriba de esta unión de contrarios, de esta fusión indefectible de fundamento e identidad, de saber y de no-saber, es la libertad que permite crear un mundo lo más exacto posible, cada vez lo más fiel a lo que el mundo demanda al mostrarse a los sentidos, no sino gracias y a través de la potencia del fundamento. En el momento en el que el Ser no escapa ya a la razón, sino que muestra a ésta de manera pormenorizada su aspecto, en ese momento el fundamento se revela como pensamiento, que en cambio se sitúa en efecto como posterius con relación al ser, pero sin el cual tampoco es posible a la vez ningún pensamiento, tal como elucida este fragmento del Tratado sobre la fuente de las verdades eternas ${ }^{64}$ :

La unidad, que aquí es común, alcanza hasta la más elevada oposición; éste es, por consiguiente, el último límite sobre el que no se puede ir. Pero en esta unidad no recae la prioridad sobre el lado del pensar. El Ser es lo primero, el pensar es lo segundo o lo consiguiente

De manera que, una vez más, todo acaba recobrando su posición, la posición al menos para la que estaba diseñado desde un comienzo, y el fundamento que sin saber muy bien qué fisionomía podía cobrar, y se conformaba con ser la figura de la conciencia, adquiere ahora el modus operandi de dicha forma, descubriéndose ahora como el pensamiento mismo, y por su parte el principio de identidad deja de estar recluido en los límites del sujeto, sino que sobre la base del fundamento mismo que es el sujeto absoluto, descubre que su función es ganar la esencia de los objetos del mundo para la conciencia que es auténticamente aquella naturaleza que es capaz de despegarse de su ipseidad primigenia y retornar sobre sí misma una vez que ha recolectado los secretos del mundo. En ese instante vuelve sobre sí ya no como una conciencia vacía y ensimismada, sino como pensamiento; es decir, como el fruto más preciado de la libertad. Tiene sentido en este momento haber emprendido la búsqueda de aquel fundamento cuya suposición era dudosa al principio, pues la investigación ha permitido el retorno a través de una serie de obstáculos que, tras salvarlos, permite finalmente «una revelación interior del Espíritu al espíritu» ${ }^{65}$; es decir, el sujeto puede reconocerse como libertad una vez que reconoce en sí mismo la capacidad de crear el mundo en el momento en que acaba descubriendo que depende de él la construcción de la identidad de lo ente, que por tanto él no era ninguna identidad, o era una identidad falsa, todavía por madurar, y que la posibilidad de edificar esa identidad bajo la forma de Sistema $(\mathrm{A}=\mathrm{A})$ radica en el hecho de que él mismo estaba separado de esa identidad que todavía no era, en el hecho de que hay un abanico entero de posibilidades para acertar con la naturaleza de las cosas, en definitiva, que se ha cursado por medio de esa separación la entera libertad de poder acometer dicho proyecto, y que es precisamente intentando cumplir con dicho plan como puede percibir al fin su esencia completamente libre.

${ }_{64}$ S. W., V, p. 769; trad. Schelling F. W. J.; «Tratado sobre la fuente de las verdades eternas», en Antología, Península, Barcelona, 1987, pp. 341-342.

${ }^{65}$ Bruatre, C.; o. c., p. 16, n. 9. 


\section{CONCLUSIÓN}

¿Qué pasa ahora con la libertad misma? ¿Puede ella conocerse como se conocen los ámbitos de cada uno de los objetos, o como se reconoce la conciencia en su fundamento después de haber coordinado estos ámbitos? La libertad tiene en Schelling, como en Kant, una naturaleza de carácter metafísico, como también sin duda otra de tipo material, aunque no es de esta última de la que aquí se trata. Y de un modo muy parecido a cómo funciona la libertad en Kant pueden llegar a tenerse indicios de cómo opera la naturaleza de la libertad (ratio essendi) a partir de la razón práctica; es decir, de las acciones puestas en obra en el mundo (ratio cognoscendi) ${ }^{66}$, pero la libertad misma es inaprehensible. Igualmente, para Schelling no existe ningún procedimiento natural gracias al cual sea posible conocer la libertad, precisamente porque la argumentación o cualquier otro producto es un dispositivo restricto que sólo puede acertar a nombrar las notas fundamentales de la libertad de un modo negativo, sin llegar nunca a saber verdaderamente qué es la libertad, cuál es su quid. Ahora bien, el punto de vista de Schelling es todavía más radical que el mantenido por Kant: ni siquiera la filosofía es una ciencia demostrativa, su cometido no es el conocimiento de ningún ámbito de lo particular, sino propiamente el de lo absoluto que concita a cada uno de los regímenes de lo concreto ${ }^{67}$. El primer paso que da la filosofía es enfangarse en la duda, en la indeterminación, en un nosaber, pero este no-saber es precisamente en lo que consiste el sujeto absoluto. El sujeto absoluto en efecto no es algo que podamos conocer como lo hacemos con el resto de objetos, y por tanto no podemos decir que lo conozcamos con la misma carga con la que decimos conozco las entrañas de la vaca o el funcionamiento de las branquias del pez, pero es en cambio gracias al sujeto absoluto que conozco el movimiento de los astros o el devuelto del volcán, pero cuando examino los planetas o los sedimentos de la lava, lo que no tengo a la vista, lo que desaparece automáticamente, es el sujeto absoluto. El sujeto absoluto, la eterna libertad no puede conocerse a través de un saber objetivo como el resto, ni siquiera a través de las acciones morales, como sí ocurre en Kant. El sujeto absoluto no está enclavado en los nudos de la existencia como si fuera un simple despojo. El sujeto absoluto es más bien, así, el asombro ante su propia ignorancia, la estupefacción ante las cosas del mundo frente a las que por el momento no puede decir una palabra, y

66 KANT, I.; Crítica de la razón práctica, A5, nota 1.

67 S. W. , V, pp. 22-23; trad. Schelling, F. W. J.; «De la nature de la philosophie en tant que science», en Essais de Schelling, Aubier, Montaigne, 1946, trad. S. Jankélévitch, p. 542, donde Schelling vuelve a explicar, con otro lenguaje, que el cometido de la filosofía es la búsqueda del absoluto. He esperado por tanto hasta aquí para sacar esta cita para despejar las dudas de aquellos que han visto cómo había introducido una cita del primer período de la filosofía de Schelling sacando a la palestra el Über die möglichkeit einer Form der Philosophie überhaupt, para mostrar que la preocupación de Schelling por el Absoluto no decae en el umbral de la filosofía positiva para pasar a ocuparse de la existencia. El ataque aquí va sobre todo dirigido, esta vez, contra Schulz, W.; o. c., p. 113, n. 7, donde se plantea que sólo en la Spätphilosophie las preocupaciones de Schelling viran hacia la libertad puesta en relación con la realidad efectiva, mientras para nosotros esta ocupación es la misma en toda la producción del filósofo, cambiando simplemente el enfoque desde el cual poder explicar dicho problema. 
ante las que no puede quedar inicialmente más que impasible. El sujeto, entonces, sólo sabe preguntar y aguardar pacientemente mientras marcha a la zaga de alguna respuesta. Esta situación en la cual el sujeto no puede ser expresado por categorías con las que mentamos a los objetos de experiencia es semejante entonces al rapto extático en el que verdaderamente el místico está perdiendo toda conexión, todo vínculo con la realidad material. La naturaleza del sujeto absoluto es por tanto análoga a la del éxtasis, como algunos comentaristas han querido ver ${ }^{68}$. Ello no quiere decir otra cosa más que el sujeto absoluto es propiamente lo activo por antonomasia, lo que tiembla de impaciencia por abocarse al mundo ${ }^{69}$. El estado del éxtasis consiste en querer comprender lo incompresible, no es por tanto el estado efectivo de la libertad aún, sino el del sujeto particular mismo que, cuando quiere juntar las palabras para expresar qué es este absoluto, este espacio lógico, el Ser, queda ridiculizado por aquello mismo que quiere alcanzar y que se le ha escapado una vez más de las manos ${ }^{70}$. No hay conocimiento entonces de la libertad absoluta, pero sí queda en cambio un rastro de lo que ella produce, lo distinto por tanto de sí, el nudo de relaciones que constituyen el mundo efectivo y que se ordena por medio de condiciones, la suprema de las cuales procede de la eterna libertad que muta en ausencia de libertad en el momento en que sale expulsada del sujeto en forma de juicio ${ }^{71}$ : incapacitados para comprender cuál es la raíz más profunda de nuestro conocimiento, en cambio, gracias a esta actividad que se despliega en nuestro interior, vemos brillar al mundo cuando logramos explicar por qué las aves circunvalan periódicamente el contorno de la tierra, o por qué las ballenas suspiran en la oquedad del mar.

68 Courtine, J.-F.; o. c., p. 192, n. 10; Challiol-Gillet, M.-C.; Schelling, une philosophie de l'extase, PUF, Paris, 1998, pp.154-157.

${ }_{69}$ KASPER, W.; Das Absolute in der Geschichte. Philosophy und Theologie der Geschichte in der Spätphilosophie Schellings, Matthias-Grünewald, 1965, Mainz, pp. 93-94, pp. 130-131, donde el éxtasis precisamente se explica como una figura que no queda al margen de los límites de una filosofía racional sino, más bien al contrario, entraña a la estructura misma de la razón donde, en el desarrollo en el que alcanza a constituirse como ciencia, su componente a priori no tiene menos una correspondencia con la necesidad del acceso a lo empírico.

${ }^{70}$ Janke, W.; Die dreifache Vollendung des Deutschen Idealismus. Schelling, Hegel und Fichtes ungeschriebene Lehre, Rodopi, Amsterdam-New York, 2009, pp. 107-108, para quien el estado ex-tático es el del grado inicial o grado 0 en el que nada se sabe, el lugar precisamente de la duda, del no-saber, pero que permite precisamente por ello el posible arranque de las proposiciones sobre el ámbito de cosas concretas que reciben la donación de la verdad gracias al principio lógico del sujeto, a la par que, recibida su adecuación con ese espacio lógico, dona también recíprocamente su validez al sujeto.

${ }_{71}$ HüHN, L.; o. c., pp. 449-450, n. 14. A esto mismo se refiere también Žižek en «Die Monstrosität des Menschen. (Schelling, Heidegger, Lacan)», en Schellings philosophische Anthropologie, 2002, Stuttgart-Bad Cannstatt, p. 84, aunque con una comprensión inversa del asunto que da precisamente más énfasis al problema de las condiciones de la libertad plena del sujeto absoluto, cuando afirma que el sujeto permanece como lo vacío antes de volcarse al mundo fenoménico, siendo en el marco de la apofansis de los fenómenos en el que el sujeto como lo absolutamente libre, se muestra como lo incomprensible por antonomasia, en tanto que deja de ser lo libre para ser lo condicionado. 


\section{BibLiografía}

\section{Fuentes originales de F.W.J. Schelling}

Schellings Werke, (1927-1954), M. Schröter. C.H. Beck/ R. Oldenburg, München (= Münchener Jubilämsdruck).

\section{Traducciones al español y otros idiomas de las obras de F. W. J Schelling}

Schelling, F. W. J. (1946). "De la nature de la philosophie en tant que science», en Essais de Schelling, Aubier, Montaigne, trad. S. Jankélévitch.

Schelling, F. W. J. (1987). Filosofía y religión, en Antología. Barcelona: Península.

Schelling F. W. J. (1987). Tratado sobre la fuente de las verdades eternas, en Antología. Barcelona: Península.

Schelling F. W. J. (1989). Investigaciones filosóficas sobre la esencia de la libertad humana y los objetos con ella relacionados. Barcelona: Anthropos. Trad. Helena Cortés y Arturo Leyte.

Schelling F. W. J. (1990). Über die möglichkeit einer Form der Philosophie überhaupt, en Experiencia e historia: escritos de juventud. Madrid: Tecnos.

Schelling F. W. J. (1993). Lecciones muniquesas para la historia de la filosofía moderna. Málaga: Edinford.

Schelling F. W. J. (1996). Escritos sobre filosofía de la naturaleza. Madrid: Alianza.

Schelling F. W. J. (1998). Filosofía racional pura, en Introduction à la philosophie de la Mythologie, trad. GDR Schellingiana. Paris: Gallimard.

Schelling F. W. J. (2006). Panorama general de la literatura filosófica más reciente. Madrid: Abada.

Schelling F. W. J. (2012). Sistema del Idealismo trascendental, en Schelling. Madrid: Gredos.

Schelling F. W. J. (2012). Las Edades del Mundo, en Schelling. Madrid: Gredos.

\section{Fuentes primarias}

Aristóteles (2000). Metafísica. Madrid: Gredos.

Aristóteles (2003). Ética a Nicómaco. Madrid: Alianza.

Fichte, J. G. (1997). Introducciones a la Doctrina de la ciencia. Madrid: Tecnos.

Kant, I. (1992). Fundamentación de la metafísica de las costumbres. Madrid: RSEM. Trad. Manuel García Morente.

Kant, I. (1997). Crítica de la razón práctica. Salamanca: Sígueme.

Kant, I. (2000). Lógica. Madrid: Akal.

Platón (2005). Menon. Madrid: Biblioteca Nueva.

\section{Fuentes secundarias}

Brito, E. (1987). La création selon Schelling. Louvain: Leuven University Press.

Bruaire, C. (1970). Schelling ou la quête du secret de l'être. Paris: Éditions Seghers.

Bowie, A. (1993). Schelling and Modern European Philosophy. London: Routledge.

Carrasco Conde, A (2011). «Panteísmo y panenteísmo: Schelling, Schlegel y la polémica en torno al panteísmo», en Daímon. Revista Internacional de Filosofía 54, pp. 93-108.

Carrasco Conde, A. (2014). «Ens alienum. El mal desde la Naturphilosophie en F. W. J. Schelling», en El vuelo del búho: estudios sobre filosofía del Idealismo, Del Luján di Sanza, S. y López, D. M. (eds.). Buenos Aires: Prometeo, pp. 241-266.

Challiol-Gillet, M.-C. (1998). Schelling, une philosophie de l'extase. Paris: PUF, Paris.

Courtine, J.-F. (1990). Extase de la raison. Essais sur Schelling. Paris: Galilée. 
Duque, F. (1999). Historia de la Filosofía Moderna. La era de la crítica. Madrid: Akal.

Düsing, K. (2001). "L'histoire idéaliste de la conscience de soi dans le Système de l'idéalisme transcendental», en Schelling et l'élan du Système de l'idéalisme trascendental, L'Harmattan, Paris, pp. 19-39.

Fischbach, F. (1999). Du commencement en philosophie. Étude sur Hegel et Schelling. Paris: Vrin.

Freydberg, B. (2008). Schelling's Dialogical. New York: Freedom Essay, SUNY.

Gabriel, M. (2010). «¿Contingencia o necesidad? Schelling y Hegel acerca del estatus modal del espacio lógico», en Ideas y valores, Vol. 59, no 142, Bogotá, pp. 5-23.

Hamilton Grant, I. (2004). "Philosophy become genetic": The Physics of the World Soul», en The new Schelling, Norman, J. y Welchman, A. (eds.). London: Continuum, pp. 128-150.

Heidegger, M. (2008). Identidad y diferencia. Barcelona: Anthropos.

Hühn, L. (1993). «Ekstasis. Überlegungen zu Schellings Spekulationen über die Grenze menschliche Wissens», en Philosophie der Subjektivität? Zur Bestimmung des neuzeitlichen Philosophierens, Akten des 1. Kongresses der Internationalen Schelling-Gesellschaft, 2, Baumgartner, H. M. y Jacobs W. G. (Hrsg.), Frommann-holzboog, Stuttgart-Bad Cannstatt, pp. 441-450.

Janke, W. (2009). Die dreifache Vollendung des Deutschen Idealismus. Schelling, Hegel und Fichtes ungeschriebene Lehre. Amsterdam-New York: Rodopi.

Kasper, W. (1965). Das Absolute in der Geschichte. Philosophy und Theologie der Geschichte in der Spätphilosophie schellings. Mainz: Matthias-Grünewald.

Kokoszka, V. (2005). La médiation de l'expérience. Paris: Cerf.

Loer, B. (1974). Das Absolute und die Wirklichkeit in Schellings Philosophie. Berlin: Walter de Gruyter.

Marquet, J.-F. (1973). Liberté et existence: Étude sur la formation de la philosophie de Schelling, Gallimard.

Pareyson (1995). En Ontologia della libertà. Il male e la sofferanza. Torino: Einaudi.

Richir, M. (2001). «Inconscient, nature et mythologie chez Schelling», en Schelling et l'élan du Système de l'idéalisme trascendental. Paris: L'Harmattan, pp. 177-189.

Roux, A. (2001). "Puissance et malheur du Moi dans le "Système de l'idéalisme trascendental" », en Schelling et l'élan du Système de l'idéalisme trascendental. Paris: L'Harmattan, pp. 123-151.

Schlanger, J. (1966). Schelling et la réalité finie. Essai sur la philosophie de la Nature et de l'Identité. Paris: P.U.F.

Schulz, W. (1955). Die Vollendung des deutschen Idealismus in der Spätphilosophie Schellings. Stuttgart: W. Kohlhammer Verlag.

Snow, D. E. (1966). Schelling and the End of Idealism. Nueva York: SUNY.

Tillich, P. (1959). Mystik und Schuldbewußtsein in Schellings philosophischer Entwicklung, en Frühe Hauptwerke. Gesammelte Werke, Band I. Stuttgart: Evangelisches Verlagswerk.

Tilliette, X. (1970). Schelling. Une Philosophie en Devenir. La Derniere Philosophie 1821-1854, Vol. II. Paris: Vrin.

Tilliette, X. (1987). L'Absolu et la philosophie. Essais sur Schelling. Paris: P.U.F.

Vetö, M. (1977). Le fondement selon Schelling. Paris: Beauchesne.

Žižek, S. (2002). «Die Monstrosität des Menschen», en Schellings philosophische Anthropologie. Stuttgart-Bad Cannstatt, pp. 75-109.

Universidad Complutense de Madrid

miguelramirezcordon@gmail.com

Miguel Ángel Ramírez Cordón

[Artículo publicado para publicación en diciembre de 2016] 